\title{
Electrochemical Reversibility of Reticulated Vitreous Carbon Electrodes Heat Treated at Different Carbonization Temperatures
}

\author{
Emerson Sarmento Gonçalves ${ }^{\mathrm{a}, \mathrm{b} *}$, Mirabel Cerqueira Rezende ${ }^{\mathrm{a}}$, \\ Marta Ferreira Koyama Takahashic, Neidenêi Gomes Ferreira ${ }^{\mathrm{d}}$ \\ ${ }^{2}$ Divisão de Materiais, AMR/IAE/CTA, Centro Técnico Aeroespacial \\ ${ }^{\mathrm{b}}$ Departamento de Aeronáutica e Mecânica, ITA/CTA, Centro Técnico Aeroespacial \\ 'Divisão de Química, AQI/IAE/CTA, Centro Técnico Aeroespacial, \\ 12228-904 São José dos Campos - SP, Brazil \\ ${ }^{\mathrm{d}}$ Laboratório Associado de Sensores, CTE/INPE, Instituto Nacional de Pesquisas Espaciais, \\ 12227-010 São José dos Campos - SP, Brazil
}

Received: February 14, 2005; Revised: March 9, 2006

\begin{abstract}
Electrochemical response of ferri/ferrocyanide redox couple is discussed for a system that uses reticulated vitreous carbon (RVC) three dimensional electrodes prepared at five different Heat Treatment Temperatures (HTT) in the range of $700{ }^{\circ} \mathrm{C}$ to $1100{ }^{\circ} \mathrm{C}$. Electrical resistivity, scanning electron microscopy and $\mathrm{X}$ ray Diffraction analyses were performed for all prepared samples. It was observed that the HTT increasing promotes an electrical conductivity increasing while the Bragg distance $d_{002}$ decreases. The correlation between reversibility behavior of ferri/ferrocyanide redox couple and both surface morphology and chemical properties of the RVC electrodes demonstrated a strong dependence on the HTT used to prepare the RVC.
\end{abstract}

Keywords: reticulated vitreous carbon, pyrolysis, $X$ ray diffraction, electrochemical properties

\section{Introduction}

Reticulated Vitreous Carbon (RVC) is an important material known by its high mechanical resistance, porosity, biocompatibility and relatively high electrical conductivity. These properties have been extensively explored in the last decades in many applications, for example, in thermal coating of airspace vehicles ${ }^{1,2}$, bony prostheses ${ }^{3}$, heart valves ${ }^{4-6}$, molecular sieves ${ }^{7}$ and hydrogenation catalyst supports $^{8}$.

Electrical conductivity variation is a determinant parameter for using RVC electrodes in many electrochemical applications. Polyaromatic hydrocarbon crystals are intrinsic semi-conductors with resistivity values between $10^{2}$ and $10^{10} \Omega$.cm. RVC characteristically shows a decrease in its electrical resistivity as a function of the manufacturing temperature increase. This behavior is associated with a better arrangement of the carbon atoms in the basal planes, forming graphitic lamellar planes, which are stacked in the carbon structure. This graphitic structure favors the transference of electrons among the hexagonal carbon rings in carbon material ${ }^{9}$. The extreme case of a polyaromatic carbon material highly arranged is the graphite single crystals. The carbon plane sheets show two-dimensional metallic conduction with resistivity values smaller than $3.3 \times 10^{-5} \Omega$.cm within the sheet and a negative temperature coefficient ${ }^{9}$. The gradual increase of conjugated carbon in the $\mathrm{sp}^{2}$ state during the heat treatment of the raw material in inert atmosphere (carbonization treatment) changes the precursor material progressively from an insulator to a good conductor in a remarkable decrease of 19 orders of magnitude in resistivity values. The electrical property is, therefore, sensitive to measure the various stages of the carbonization treatment and provide information about the final structure of carbon ${ }^{9}$. Yamaguchi ${ }^{10-12}$ made the first measurements of electrical resistivity of vitreous carbon obtained from heat treatment temperatures between $800{ }^{\circ} \mathrm{C}$ and $3200{ }^{\circ} \mathrm{C}$.
The electrical resistivity behavior of vitreous carbon derived from phenolic resin, at room temperature, assessed by potentiometric method, was described by Jenkins et al. ${ }^{9}$. The resistivity decreases rapidly up to $900{ }^{\circ} \mathrm{C}$. Afterwards, it decreases gradually reaching a constant value at $1500{ }^{\circ} \mathrm{C}$, comparable to that of well-graphitized material with crystallite size greater than $1000 \AA$.

Additionally, the literature shows that the conductivity of solid carbons reaches a similar value in the same temperature range, between $600{ }^{\circ} \mathrm{C}$ and $700{ }^{\circ} \mathrm{C}$, when the carbon loses its acid proper$\operatorname{ties}^{13-18}$. The properties of solid carbon surface are strictly related to heteroatoms, which are removed during the heat-treatment, as water (up to $400{ }^{\circ} \mathrm{C}$ ), $\mathrm{CO}_{2}$ (up to $700{ }^{\circ} \mathrm{C}$ ), $\mathrm{CO}$ (up to $1200{ }^{\circ} \mathrm{C}$ ), $\mathrm{H}_{2}$ and $\mathrm{CH}_{4}$ (above $950{ }^{\circ} \mathrm{C}$ ), and also nitrogenated and sulfonated forms (above $\left.1800{ }^{\circ} \mathrm{C}\right)^{13-15,19-23}$. Therefore, the acid functionality loss (initially by $\mathrm{CO}_{2}$ ) approximately coincides with the trend of electrical conductivity to keep nearly constant for solid carbons. These factors are presumably related to the effects of electron delocalization, which favors electrical conduction that becomes higher after the acid group loss.

Furfuryl alcohol resin is a polymer of national production and it usually presents low volatile losses during curing and carbonization processes. These characteristics induce to the more dense final carbonized foam (RVC) stems and, consequently, with higher mechanical properties (for example more resistant to flexion efforts) and lower electrical resistivity than those obtained from phenolic resins.

This work aims to systematically describe the morphological and structural properties of RVC three dimensional electrodes, produced from furfuryl alcohol resin at different HTT, by SEM and XRD measurements. Electrical resistivity of RVC samples is also correlated with its electrochemical response, evaluating the reversibility behavior for the ferri/ferrocyanide redox couple. 


\section{Experimental}

RVC was obtained by impregnation of a polyether based polyurethane (PU) foam, commercially available, by using furfuryl alcohol resin (dynamic viscosity of $\sim 3.0 \mathrm{~Pa} \mathrm{~s}$ ). Using p-toluenossulfonic acid as catalyst $(3 \% \mathrm{w} / \mathrm{w})$ the resin cure process was carried out. Furfuryl alcohol resin cure cycle was performed at $60^{\circ} \mathrm{C}$ and this temperature was kept for 2 hours. Afterwards, the temperature was raised up to $80{ }^{\circ} \mathrm{C}$ for 2 hours. Then, the samples show suitable mechanical resistance to be manipulated and machined in different shapes.

To evaluate the influence of the maximum HTT on the RVC properties the cured resin was carbonized up to five different maximum temperatures, between $700^{\circ} \mathrm{C}$ and $1100{ }^{\circ} \mathrm{C}$. The samples were heated at $1.0{ }^{\circ} \mathrm{C} \mathrm{min}{ }^{-1}$ under a nitrogen flow of $1 \mathrm{~L} . \mathrm{h}^{-1}$, from room temperature until the selected maximum temperature. This step took nearly 30 minutes. The cooling occurred naturally up to room temperature.

The RVC superficial morphology analyses were performed by Scanning Electronic Microscopy (SEM) by using the equipment Zeiss DSM/950. Structural analyses were carried out by $\mathrm{X}$ ray Diffraction (XRD) in a diffractrometer Phillips, PW 1210/W/380/80.

Electrical resistivity measurements were carried out according to the four-probe method ${ }^{24}$. The samples were kept linked to a tension measurer HP 34401A and a continuous current generator Tectrol TC-50-015. RVC samples were shaped into rectangular bars with the longest axis being the axis of the resistivity measurements. Silver paint was used for improving the electrical contacts. The compact volume electrical resistivity $(\rho)$ was determined as a function of the inner probe separation.

FTIR (Fourier Transformed Infrared) spectra were performed by using a spectrophotometer SPECTRUM 2000 - Perkin Elmer, in the region of $4000-400 \mathrm{~cm}^{-1}$. The spectra were obtained by Photoacustic Spectroscopy (PAS) technique.

Cyclic Voltammetry (CV) measurements were carried out by using a Microquimica potentiostat MQPG- 01 in $1 \mathrm{mM}$ of ferrocyanide $/ 0.1 \mathrm{M} \mathrm{KCl}$, at scan rates of 5 to $500 \mathrm{mV}^{-1} \mathrm{~s}^{-1}$. The experiments were performed at room temperature in normal atmosphere. A simple three-electrode (WE - Working Electrode, CE - Counter Electrode of Pt mesh, RE - Reference Electrode of $\mathrm{Ag} / \mathrm{AgCl}$ ) and a singlecompartment electrochemical cell were used in this study. The $\mathrm{CE}$ was positioned in front of the WE one. The RE was positioned close to the WE one, in the opposite side of the CE. The WE was prepared by machining RVC pieces in rectangular shape with dimensions of $14.3 \mathrm{~mm} \times 12.6 \mathrm{~mm} \times 7.02 \mathrm{~mm}$, respectively. For all experiments, the $\mathrm{RE}$ was $\mathrm{Ag} / \mathrm{AgCl}$. The solution was not stirred during the voltammetry experiments. The end of the electrodes was assembled over one brass base and the electrical contact was adapted by using silver based paste to improve the electrical contact. The electrodes were not submitted to superficial pre-treatment before the electrochemical measurements and their behaviors were registered in the first $\mathrm{CV}$ cycle.

\section{Results and Discussion}

\subsection{Morphology and microstructure}

Images obtained by SEM do not reveal large differences among the RVC structures manufactured at different HTT. However, the bubble formation is remarkable in the temperature range of $700{ }^{\circ} \mathrm{C}$ and $800^{\circ} \mathrm{C}$, as shown in Figure 1a,b. SEM images of the RVC samples, with magnification of 20 times, (Figure 1c) allow estimating the pore diameters and its distribution considering pores per inch (ppi). This figure shows that the RVC is rich in transport pores with robust stemsthat guarantees its handling. Figure 1d depicts a small region of the vitreous carbon stem treated at $1100{ }^{\circ} \mathrm{C}$. This typical image shows a smooth aspect of the vitreous carbon and no bub- ble presence. Generally speaking, the manufactured RVC presents macropores with average diameter of $460 \mu \mathrm{m}$, which correspond to around $50 \mathrm{ppi}$. This value is important to estimate the specific geometric surface area of electrode. Friedrich et al. ${ }^{25}$ measured the effective area of the pore stems by SEM and found a linear relation between the quantity of ppi and the specific surface area. By using this relation a specific area of $31.0 \mathrm{~cm}^{2} \mathrm{~cm}^{-3}$ was evaluated for the 50 ppi-RVC sample tested in this work.

Figure 2 presents the resistivity behavior as a function of HTT. This analysis is commonly presented in literature ${ }^{6}$, but it does not involve the electrochemical response of the electrodes. In Figure 2 an abrupt decrease of the resistivity values is observed. This value is nearly ten times higher for the RVC sample treated at $700{ }^{\circ} \mathrm{C}$ than the one treated at $800{ }^{\circ} \mathrm{C}$. Above this temperature (up to $1100{ }^{\circ} \mathrm{C}$ ) the resistivity values show no significant variation. Usually, to explain these results, the classical approach used for semiconductor conductivity is applied ${ }^{26}$. This consideration is associated with the presence of energy gaps of two different origins, i.e., the intrinsic gap and one caused by impurities or lattice defects attributed to crystalline structure distortions. The later, as a chemical effect, decreases as the temperature increases and it is correlated to the fact that lower HTT does not offer sufficient energy for eliminating bonds $\mathrm{C}=\mathrm{C}$ and functional groups $\mathrm{C}=\mathrm{O}$. The presence of these functionalities on the RVC surface $(\mathrm{C}=\mathrm{C}$ and $\mathrm{C}=\mathrm{O})$ was determined by FTIR analysis for the samples treated at $700{ }^{\circ} \mathrm{C}$, as shown in Figure 3. This figure shows contributions of $\mathrm{C}=\mathrm{C}$ and $\mathrm{C}=\mathrm{O}$ at $1700-1500 \mathrm{~cm}^{-1}$. The presence of an intrinsic gap is explained by graphite-like ribbon distortions. Additionally, the bubbles present in Figure 1a,b, which represent vacancies, can also promote the conductivity decrease.

$\mathrm{X}$ ray diffraction measurements have proved to be an important technique for RVC structural analysis. Considering the model proposed by Kawamura and Jenkins ${ }^{27}$ for vitreous carbon structure, the main purpose of these measurements is to evaluate both the development of carbon layers ${ }^{28}$ and the character of their mutual ordering 29 . It is known that the profiles of $(h k)$ reflections correspond to the model of flat rectangular anisotropic Coherently Scattering Domains (CSD). The heat treatment results in anisotropic growth of $\mathrm{CSD}^{29}$. Figure 4 shows the determined values for both the distances between the lamellar planes $\left(d_{002}\right)$ and the plane stacking sizes $\left(L_{002}\right)$ evaluated from XRD spectra. The analysis of (002) reflections evidences a sharp reduction of interlayer distance from $0.377 \mathrm{~nm}$ to $0.364 \mathrm{~nm}$ between $700{ }^{\circ} \mathrm{C}$ and $1100{ }^{\circ} \mathrm{C}$. These results may be explained from two important contributions. The first involves the volatile release trapped in the material and the second the rearrangement of graphitic lamellar planes. The simultaneous occurrence of these two phenomena leads to a more organized carbon strucutre, as described in literature ${ }^{9}$. In this same temperature interval $L_{002}$ changes from $0.698 \mathrm{~nm}$ up to $0.848 \mathrm{~nm}$, confirming the crystallinity increase as a function of the HTT. This is related to the repulsive interaction decrease between the clouds of $\pi$-electrons of adjacent graphitic layers, allowing these layers to come closer. In fact, the release of both oxygenated groups and olefin bonds provides a decrease in the electronic cloud density, responsible for the repulsion among layers. Besides, these groups and bonds represent a volumetric impediment which leads to the Bragg distance decreasing. This interpretation confirms the mechanism proposed by Fitzer et al..$^{31,32}$.

\subsection{Electrochemical behavior}

Cyclic voltammetry analysis has been widely used to characterize different types and shapes of carbon electrodes ${ }^{9,13}$. A series of experiments was carried out to study the electrochemical behavior of RVC electrodes in ferrocyanide redox couple. The main objective was to 


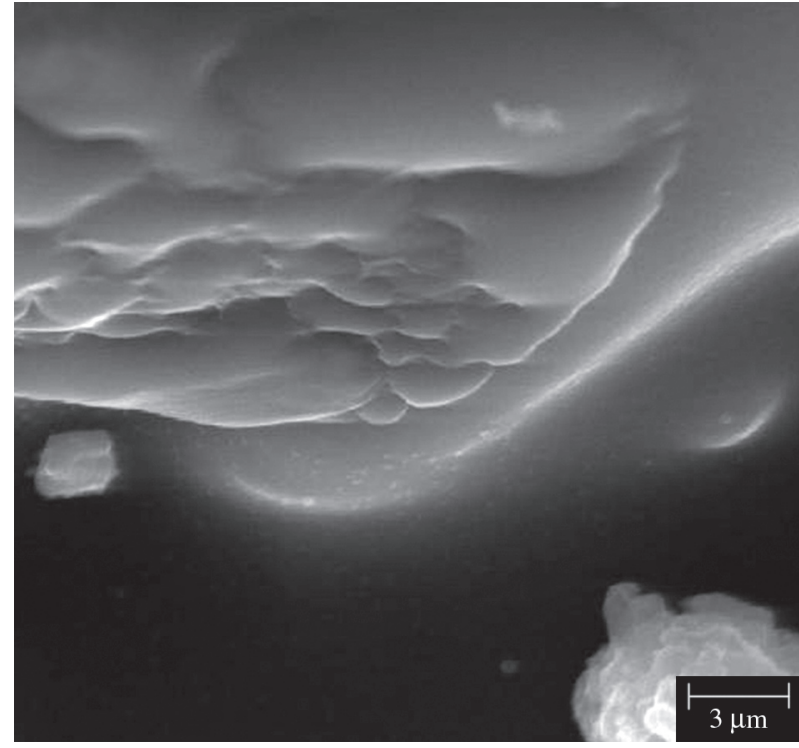

(a)

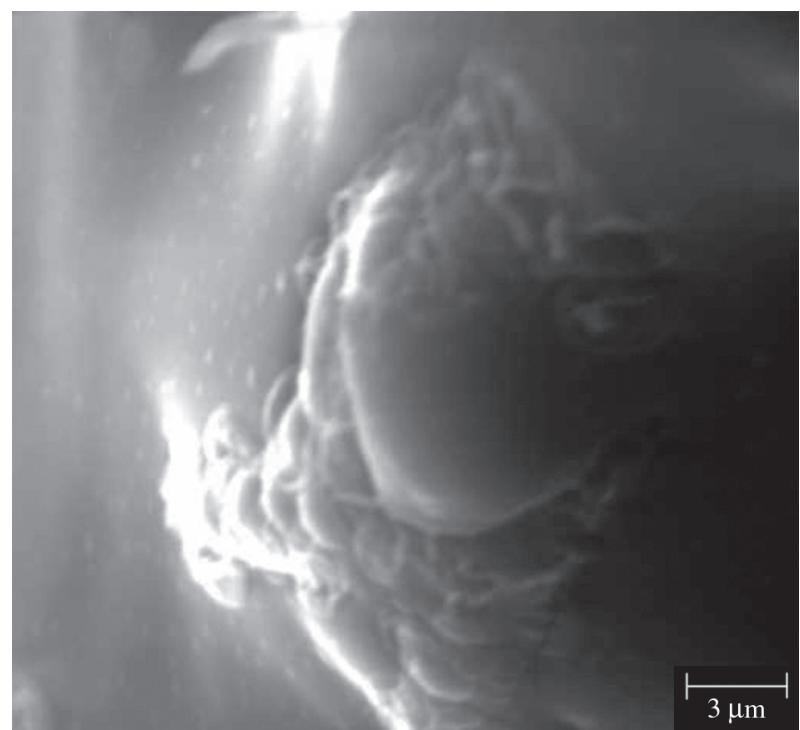

(b)

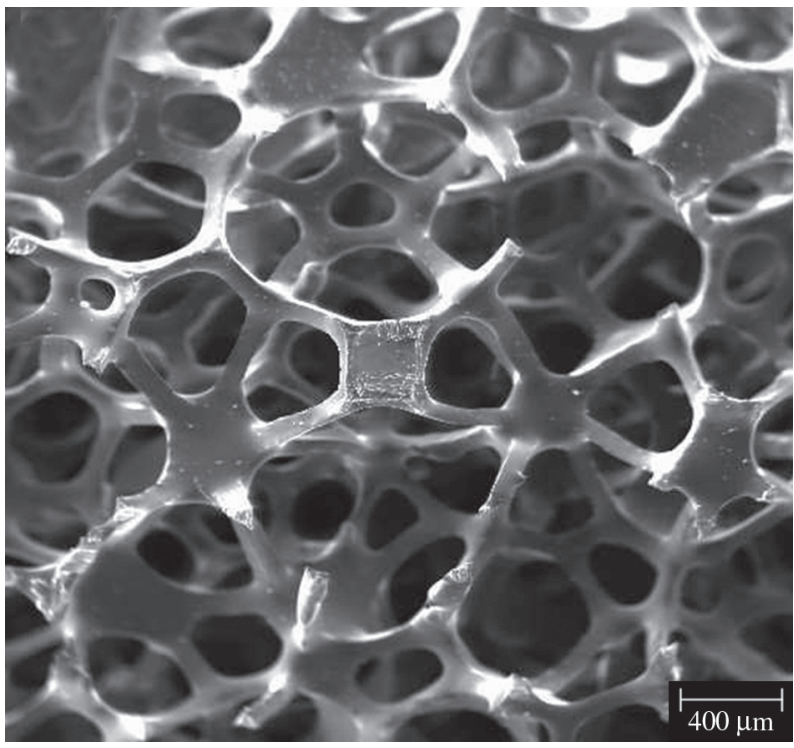

(c)

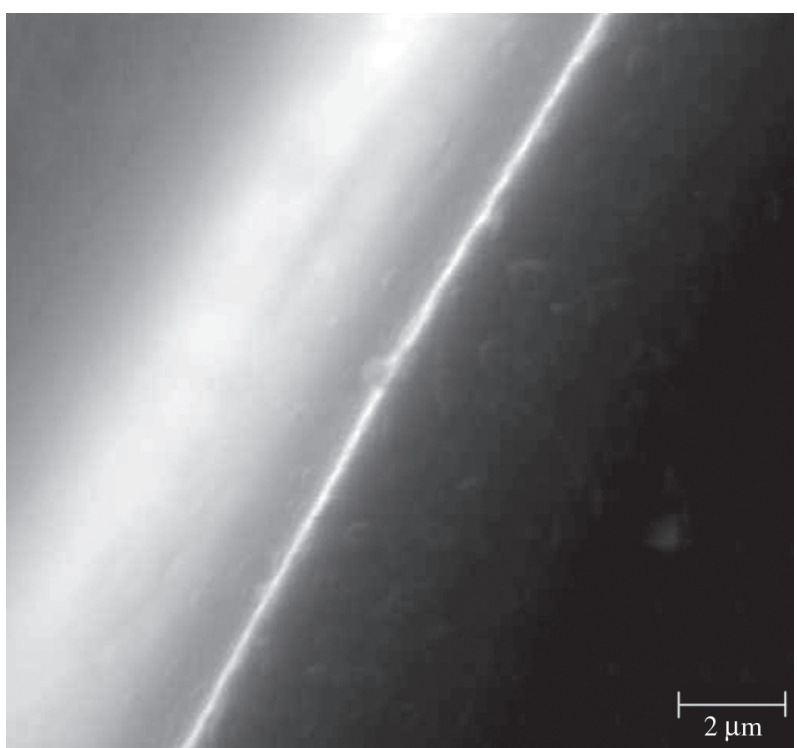

(d)

Figure 1. SEM images of RVC samples heat treated at: a) $700{ }^{\circ} \mathrm{C}-3000 \mathrm{X}$; b) $800{ }^{\circ} \mathrm{C}-3000 \mathrm{X}$; c) $800{ }^{\circ} \mathrm{C}-20 \mathrm{X}$; and d) $1100{ }^{\circ} \mathrm{C}-5000 \mathrm{X}$.

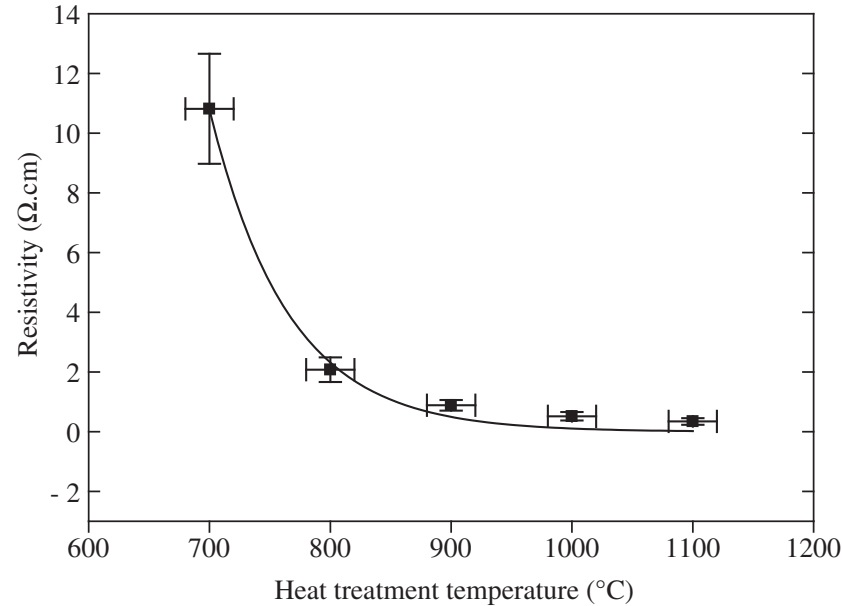

Figure 2. Resistivity behavior of RVC as function of the maximum temperature used in its manufacture.

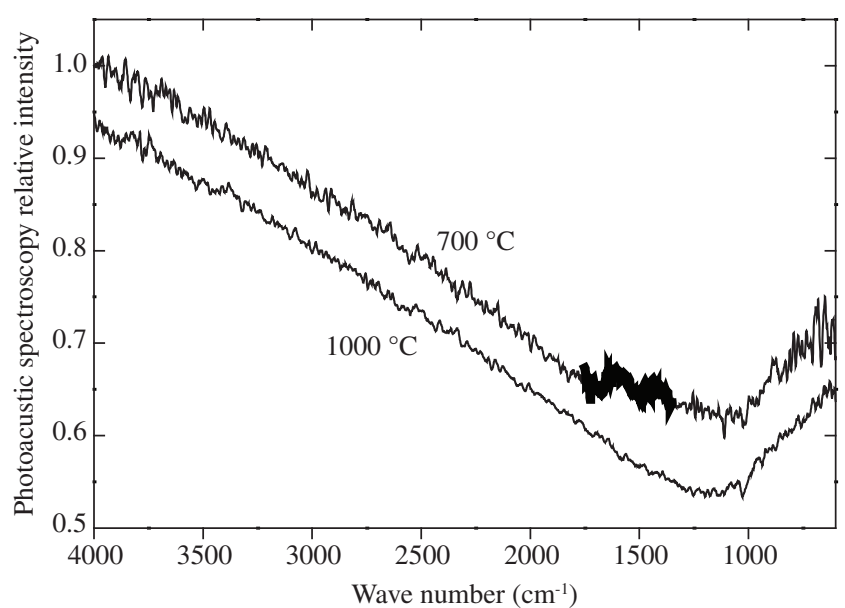

Figure 3. FT-IR spectra of RVC samples heat treated at $700{ }^{\circ} \mathrm{C}$ and $1000{ }^{\circ} \mathrm{C}$. The interval between 1700 and $1100 \mathrm{~cm}^{-1}$ suggest the presence of functionalities. The relevant contributions are marked in spectrum. 
verify the electrode response agreement using some criteria of quasi reversibility for the usual redox reactions in this electrolyte ${ }^{33}$. The correlation between morphological and structural results previously discussed and the voltammetric data supports the consistency of this study. Electrochemical response also permitted to evaluate the Specific Electrochemical Surface Area (SESA) of the RVC electrodes. The results have shown a strong dependence between the HTT and the reversibility behavior, as expected. This method represents an additional technique for controlling the RVC electrode quality. To understand the next approach, the following notion was used: $S_{s}$ for the specific surface area $\left(\mathrm{cm}^{2} \mathrm{~cm}^{-3}\right) ; I_{p}$ for the anodic peak current intensity (A); $C_{o}$ for the oxidant concentration (equal to reductor); $V_{e l}$ for the electrode volume immersed in solution $\left(\mathrm{cm}^{3}\right) ; D_{o}$ for the oxidant difusivity in solution ( $\mathrm{cm}^{2} \mathrm{~s}^{-1}$, also considered equal to reductor), and $v$ for the sweeping rate in voltammetric experiments $\left(\mathrm{V} . \mathrm{s}^{-1}\right)$.

The voltametric studies show that the RVC electrodes may be analyzed by quasi-reversibility criteria: $I_{p}$ increases with $v^{1 / 2}$ but does not keep the proportionality; $\Delta E_{p}$ is larger than $59 / n \mathrm{mV}$ and it increases with $v$; and the cathodic peak potential, $E_{P c}$, shifts to negative value when $v$ increases. This analysis was associated with the kinetic parameters $\Delta E_{p}$ and $I_{P_{c}}$ as function of both HTT and sweeping rate $^{33}$. The treatment of systems called quasi-reversible is associated with reactions that show electron transfer kinetic limitations where the reverse reaction must be considered. The results obtained in the performed experiments led to conclude that this consideration is the most suitable treatment for such RVC electrodes in the studied redox system, mainly due to the range of $\Delta E_{P}$ obtained as a function of the sweeping rates.

Figure 5 presents voltammetric curves for a RVC electrode treated at $800{ }^{\circ} \mathrm{C}$ in $1 \mathrm{mM}$ of ferrocyanide $/ 0.1 \mathrm{M} \mathrm{KCl}$. For all electrodes, it was observed that the sweeping rate increase promotes an increase of the current peak intensity in cathodic and anodic reactions. The

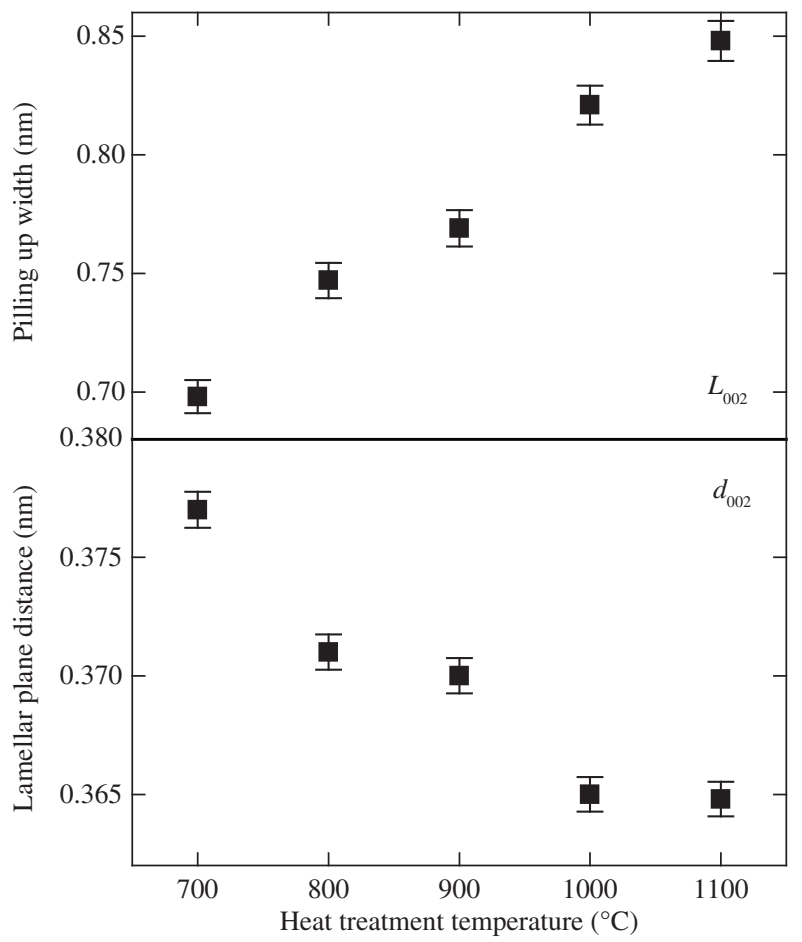

Figure 4. Lamellar planes $d_{002}$ and pilling up width $L_{002}$ obtained from XRD analysis. anodic peak shifts from $0.290 \mathrm{~V}$ to $0.420 \mathrm{~V}$ and the cathodic peak shifts from $0.24 \mathrm{~V}$ to $0.0752 \mathrm{~V}$. Only some curves are shown for a better visualization.

The anodic peak current is also used to evaluate the specific electrochemical surface area, which is obtained by Equation $1^{34}$ :

$$
\mathrm{SESA}=\frac{I_{p}}{2.69 \times 10^{5} C_{o} V_{e l} \sqrt{D_{o} v}}
$$

where: SESA values are shown in Figure 6. These values are in good agreement with Friedrich et al. ${ }^{25}$, for samples heat treated at temperatures of $1000{ }^{\circ} \mathrm{C}$ and $1100{ }^{\circ} \mathrm{C}$, considering the area measurements of the foam stems. The apparent disagreement for lower HTT samples may be explained by two important contributions. The lower HTT provides larger resistive effect as exposed in Figure 2, which is determinant for the electrode electrochemical response. Besides, the influence of the measured current may also contain an unknown contribution from surface modifications of the electrode ${ }^{34}$. FTIR analysis supports this argument by detecting carbonyl groups and olefin bonds that represent modifications on carbon surface for samples heat treated at $700{ }^{\circ} \mathrm{C}$. The micrometric bubbles observed by SEM are an additional factor which may represent important roughness effect. Consequently, the surface

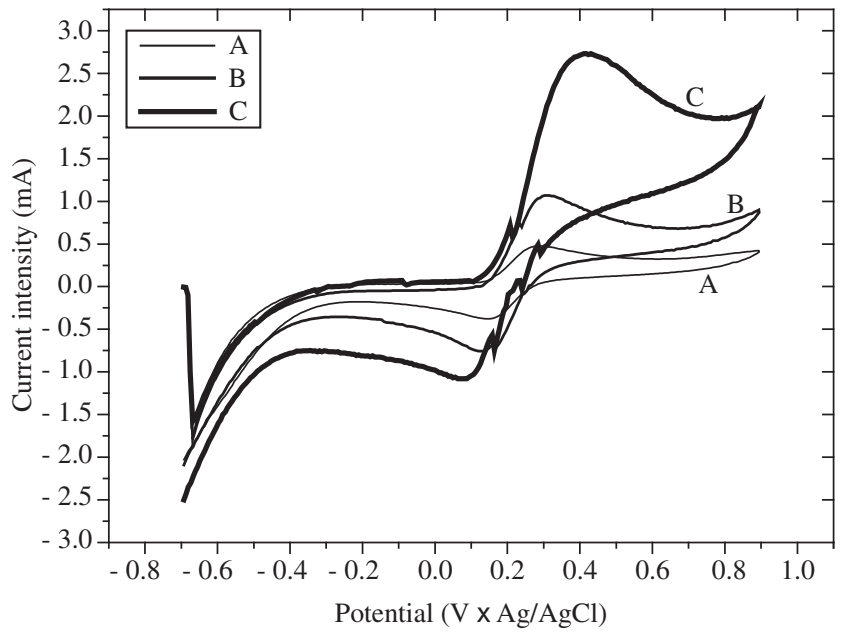

Figure 5. Cyclic voltammetric behavior of RVC electrode heat treated at $800{ }^{\circ} \mathrm{C}$ in $1 \mathrm{mM}$ Ferrocyanide/ $0.1 \mathrm{M} \mathrm{KCl}$. Each voltammogram is related to one sweep rate: $\mathrm{A}=5 \mathrm{mV} \cdot \mathrm{s}^{-1} ; \mathrm{B}=50 \mathrm{mV} \cdot \mathrm{s}^{-1}$; and $\mathrm{C}=500 \mathrm{mV} \cdot \mathrm{s}^{-1}$.

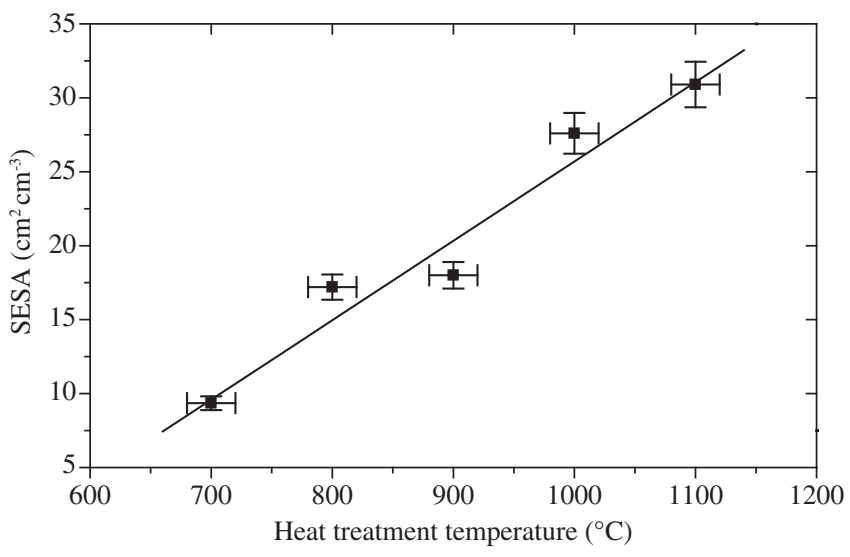

Figure 6. Specific electrochemical surface areas (SESA) for RVC electrodes manufactured at different $\mathrm{HTT}$ (from $700{ }^{\circ} \mathrm{C}$ up to $1100{ }^{\circ} \mathrm{C}$ ). 
area value evaluated through this process will not represent the real area of such electrode.

By using the quasi-reversibility criteria, $\Delta E_{p}$ shows a slightly increase (for the samples heat treated at $800-1100{ }^{\circ} \mathrm{C}$ ) with the sweeping rate increase and it is larger than $59 / n \mathrm{mV}$ (where $n=1$ is the number of electrons involved in the reaction) (Figure 7), assisting an approach of quasi reversibility. Another important aspect is related to the cathodic peak variation: the current increases with $v^{1 / 2}$, as shown in Figure 8. From this figure it is possible to observe the irreversibility of the system assembled with RVC electrodes heat-treated at the maximum temperature of $700{ }^{\circ} \mathrm{C}$. This is observed by considering that the peak current profile does not increase in function of $v^{1 / 2}$ if compared with the pronounced increase observed for the RVC electrodes treated at higher temperatures. The carbonyl groups and olefin bonds determined by FTIR analysis for the samples heat treated at $700{ }^{\circ} \mathrm{C}$, associated to the bubble presence on the steam surfaces, justify this significant difference observed for the electrochemical behavior of such samples. Firstly, the bubbles provide an increase of the void volume that hinders the electron transport. Also, the presence of oxygenated groups such as carbonyl, carboxyl, lactones and quinones is related in literature ${ }^{35}$. Presence of methilenical bonds decreases the conductivity because it constitutes an electronic barrier from $\mathrm{sp}^{3}$ hybridization. However, it is known that the presence of acid groups in samples does not necessarily provide resistivity changes, but decreases the cathodic character of vitreous carbon. Figure 9 reveals that $\Delta E_{p}$ is larger only for electrodes heat treated at $700{ }^{\circ} \mathrm{C}$, indicating the inadequacy of this treatment for obtaining a good electrode. For HTT higher than $900{ }^{\circ} \mathrm{C}, \Delta E_{p}$ is $0.2 \mathrm{~V}$, nearly six times lower than that determined for the sample treated at $700{ }^{\circ} \mathrm{C}$. This electrochemical behavior is similar in the whole range of sweeping rate studied.

\section{Conclusions}

RVC electrodes obtained from different heat treatment temperatures were studied by correlating their morphology, structure, electrical resistivity and electrochemical response. $\mathrm{X}$ ray diffraction and resistivity measurements have demonstrated to be important tools for studding the RVC electrode properties. Besides, electrochemical study has shown to be adequate for detecting electroactive species and revealing a quasi-reversible behavior for such electrodes, except for samples heat treated at $700{ }^{\circ} \mathrm{C}$. This sample, which presents carbonyl groups, showed by cyclic voltammetry the lowest anodic and cathodic current peaks and the largest $\Delta E_{p}$, mainly correlated to its higher resistivity. This effect provides voltammograms without peaks and with the highest inclination, revealing worthless faradic current peaks. Finally, the evaluation of the specific electrochemical area is strongly affected by the electrode resistivity. For the samples manufactured by using HTT values higher than $800{ }^{\circ} \mathrm{C}$, with lower resistivity values, a SESA was found in good agreement with the values shown by Friedrich et al. ${ }^{25}$. The resistive component of voltammograms in the temperature range of $700-800{ }^{\circ} \mathrm{C}$ is more intense for carbon treated at lower HTT, influencing the electrochemical responses. This behavior is probably related to the presence of methilenical bonds and oxygenated groups from furfuryl alcohol resin used as raw material in the RVC processing.

\section{Acknowledgments}

The authors would like to thank A. O. Santos for SEM images, A. V. Diniz from LAS/INPE for X ray diffraction measurements and FAPESP (Process number: 05/50718-9) and CNPq (Process number: 303528/2003-6). We are specially grateful to E. C. Botelho for improving the technical discussion of this work.

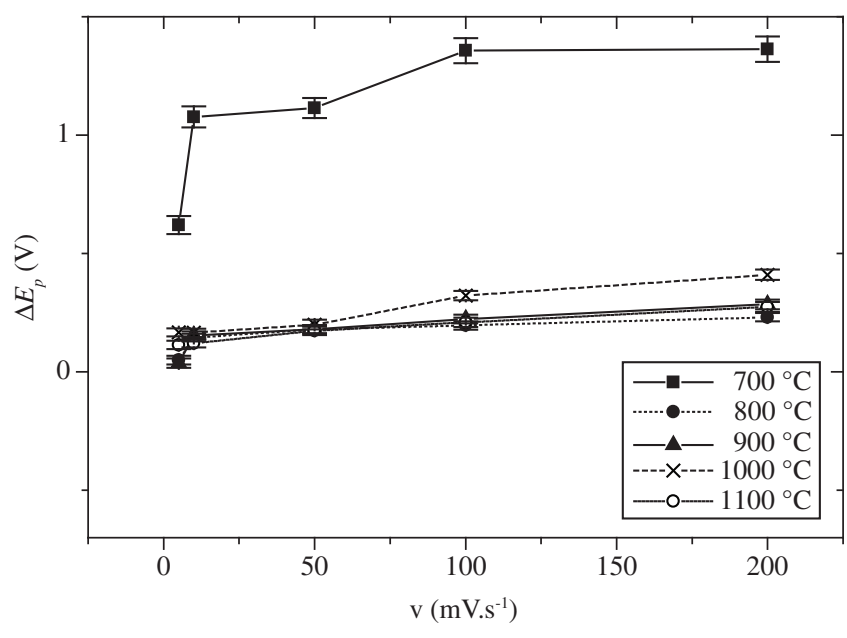

Figure 7. $\Delta E_{p}$ as a function of sweep rate in $1 \mathrm{mM}$ Ferrocyanide/ $0.1 \mathrm{M} \mathrm{KCl}$ for RVC electrodes manufactured at different HTT (from $700{ }^{\circ} \mathrm{C}$ up to $\left.1100{ }^{\circ} \mathrm{C}\right)$.

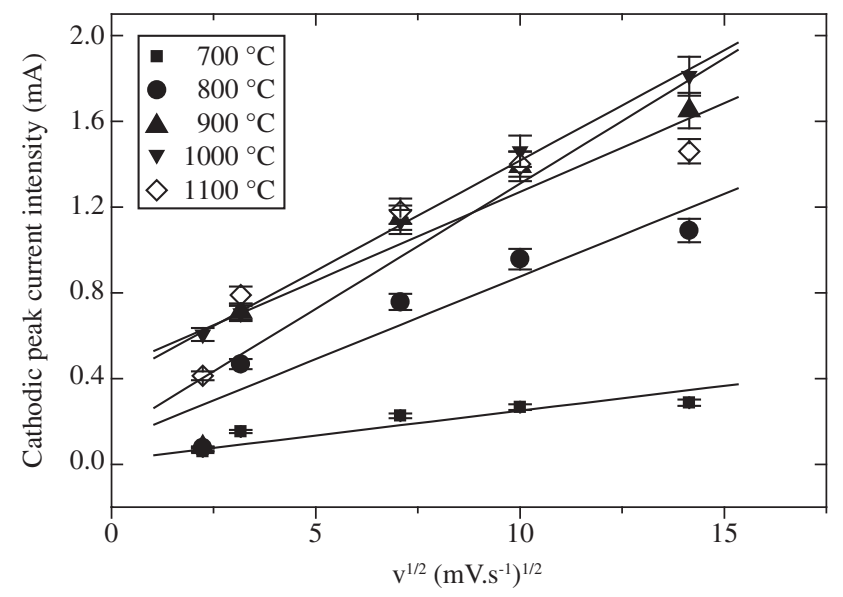

Figure 8. Cathodic peak current as a function of (sweep rate) $)^{1 / 2}$ in $1 \mathrm{mM}$ Ferrocyanide/0.1 M KCl for RVC electrodes manufactured at different HTT (from $700{ }^{\circ} \mathrm{C}$ up to $1100{ }^{\circ} \mathrm{C}$ ).

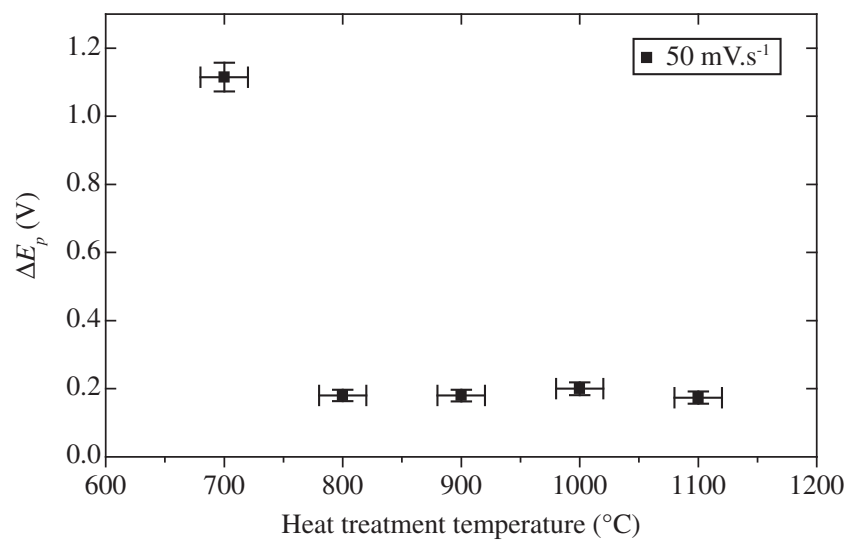

Figure 9. $\Delta E_{p}$ as a function of HTT used in the RVC electrode manufacture, in $1 \mathrm{mM}$ Ferrocyanide/ $0.1 \mathrm{M} \mathrm{KCl}$ at sweep rate of $50 \mathrm{mV} \cdot \mathrm{s}^{-1}$. 


\section{References}

1. Bradshaw WG, Pinoli PC, Mitchell MJ. Recent Developments in glassy carbon fabrication. In: Proceedings of $9^{\text {th }}$ Biennial Conference on Carbon; 1969; Boston: USA. Boston: American Carbon Society; 1969. p. 7.

2. Bunnell LR. Proc. Vitreous carbon matrix carbon-carbon composite by copyrolysis. In: Proceedings of $12^{\text {th }}$ Biennial Conference on Carbon; Pennsylvania; 1975; USA. Pennsilvania: American Carbon Society; 1975. p. 333-334

3. Kaplan RB. Open cell tantalum structures for cancellous bone implants and cell and tissue receptors. US Patent 5282861; 1994.

4. Rezende MC. Produção de Carbono Vítreo, em Escala de Laboratório, a partir de Resinas Furfurílica e Fenólica. São Paulo: Brazil. [Doctoral Thesis]. São Paulo, EPUSP; 1991.

5. Bokros JC. Carbon biomedical devices. Carbon. 1977; 15(6):353.

6. Jenkins GM, Grigson CJ. The fabrication of artifacts out of glassy carbon and arbon-fiber-reinforced carbon for biomedical applications. J. Biomed. Mater. Res. 1979; 13:371-394.

7. Schmitt Jr JL, Walker PL. Carbon molecular sieve supports for metal catalysts-II. Selective hydrogenation of hydrocarbons over platinum supported on polyfurfuryl alcohol. Carbon. 1972; 10(1):87-92.

8. Cooper BJ, Trimm DL. Selectivity of carbon molecular sieve supported catalysts. In: Preprint $3^{\text {rd }}$ Conference on Industrial Carbon and Graphite; 1970; London: UK. London: Soc. Chem. Ind.; 1970. p. 49.

9. Jenkins GM, Kawamura K. Polymeric carbons - carbon fibre, glass and char. Cambridge: Cambridge University Press; 1976. p. 83-108

10. Yamaguchi T. Galvanomagnetic properties of glassy carbon. Carbon. 1964; 1(1):47-50.

11. Yamaguchi T. Thermoelectric power of glassy carbon at high temperature. Carbon. 1964; 1(4):535-536.

12. Yamaguchi T. Electronic Properties of Carbonized Polyacrylonitrile Fibers. Carbon. 1964; 2(1):95-96.

13. Leon y Leon CA, Radovic LR. Interfacial Chemistry and Electrochemistry of Carbon Surfaces. In: Thrower PA, editor. Chemistry and physics of carbon; New York: USA. New York: Dekker. 1994; 24:213-310.

14. Rivin D. Surface Properties of Carbon. Rubber Chem. Technol. 1971; 44:307-343.

15. Rivin D. Carbon Black Iodination. Extended Abstract, in Proc. $5^{\text {th }}$ Conf. on Carbon; 1963; New York: USA. New York: Pergamon Press; 1963. v. 2. p. 199.

16. Papirer E, Li S, Donnet JB. Contribution to the study of basic surface groups on carbons. Carbon. 1987; 25(2):243-247.

17. Papirer E, Dentzer J, Li S, Donnet JB. Surface groups on nitric acid oxidized carbon black samples determined by chemical and thermodesorption analyses. Carbon. 1991; 29(1):69-72.
18. Puri BR. Surfaces complexes on Carbons. In: Walker, Jr PL, editor. Chemistry and physics of carbon; New York: USA. New York: Dekker. 1970; 6:191-282.

19. Kinoshita K. Carbon: Electrochemical and Physicochemical Properties, New York: Wiley, p. 1-17, 86-91, 1988.

20. Morimoto T, Miura K. Adsorption sites for water on graphite. 1. Effect of high-temperature treatment of sample. Langmuir. 1985; 1(6):658-662.

21. Morimoto T, Miura K. Adsorption sites for water on graphite. 2. Effect of autoclave treatment of sample. Langmuir. 1986; 2(1):43-46.

22. Miura K, Morimoto T. Adsorption sites for water on graphite. 3. Effect of oxidation treatment of sample. Langmuir. 1986; 2(6):824-828.

23. Miura K, Morimoto T. Adsorption sites for water on graphite. 4. Chemisorption of water on graphite at room temperature. Langmuir. 1988; 4(6): $1283-1288$

24. Shui X, Frysz CA, Chung DDL. Solvent cleansing of the surface of carbon filaments and its benefit to the electrochemical behavior. Carbon. 1995; 33(12):1681-1698.

25. Friedrich JM, Ponce-de-León C, Reade GW, Walsh FC. Reticulated vitreous carbon as an electrode material. Journal of Electroanalytical Chemistry. 2004; 561(1):203-217.

26. Pesin LA. Review - Structure and properties of vitreous carbon. J. Matter. Sci. 2002; 37:1-28.

27. Kawamura K, Jenkins GM. Structure of Glassy Carbon. Nature. 1971; 231:175-176

28. Fischbach DB. The Kinetics and Mechanism of Graphitization. In: Walker, Jr PL, editor. Chemistry and physics of carbon; New York: USA. New York: Dekker. 1971; 7:1-105.

29. Rousseaux F, Tchoubar D. Structural evolution of a glassy carbon as a result of thermal treatment between 1000 and $2700{ }^{\circ} \mathrm{C}-\mathrm{I}$. Evolution of the Layers. Carbon. 1977; 15(2):55-61.

30. Hagio T, Nakamizo M, Kobayashi K. Studies on X-ray diffraction and Raman spectra of B-doped natural graphite. Carbon. 1989; 27(2):259263.

31. Fitzer E, Schafer W, Yamada S. The formation of glasslike carbon by pyrolysis of polyfurfuryl alcohol and phenolic resin. Carbon. 1969; 7(6):643-646.

32. Fitzer E, Schafer W. The effect of crosslinking on the formation of glasslike carbons from thermosetting resins. Carbon. 1970; 8(3):353-364.

33. Greef R, Peat R, Peter LM, Pletcher D, Robinson J. Instrumental Methods in Electrochemistry, New York: Wiley; 1985. p. 178-227.

34. Trassatti S, Petrii OA. Real Surface Area Measurements in Electrochemistry. Pure \& Appl. Chem. 1991; 5(5):711-734.

35. Fabish TJ, Schleifer DE. Surface chemistry and the carbon black work function. Carbon. 1984; 22(1):19-38. 